\title{
Medication therapy management clinic: perception of healthcare professionals in a University medical center setting
}

Mansi SHAH, Anna MARKEL VAYSMAN, Lori WILKEN. Received (first version): 24-Apr-2013 Accepted: 28-Aug-2013

\begin{abstract}
${ }^{*}$
Objective: To determine the overall perception and utilization of the pharmacist managed medication therapy management (MTM) clinic services, by healthcare professionals in a large, urban, university medical care setting.

Methods: This was a cross-sectional, anonymous survey sent to 195 healthcare professionals, including physicians, nurses, and pharmacists at The University of Illinois Outpatient Care Center to determine their perception and utilization of the MTM clinic. The survey consisted of 12 questions and was delivered through a secure online application.
\end{abstract}

Results: Sixty-two healthcare professionals (32\%) completed the survey. $82 \%$ were familiar with the MTM clinic, and $63 \%$ had referred patients to the clinic. Medication adherence and disease state management was the most common reason for referral. Lack of knowledge on the appropriate referral procedure was the prominent reason for not referring patients to the MTM clinic. Of the providers that were aware of MTM services, $44 \%$ rated care as 'excellent', $44 \%$ as 'good', $5 \%$ as 'fair', and $0 \%$ stated 'poor'. Strengths of MTM clinic identified by healthcare providers included in-depth education to patients, close follow-up, and detailed medication reconciliation provided by MTM clinic pharmacists. Of those familiar with MTM clinic, recommendations included; increase marketing efforts to raise awareness of the MTM clinic service, create collaborative practice agreements between MTM pharmacists and physicians, and ensure that progress notes are more concise.

Conclusion: In a large, urban, academic institution MTM clinic is perceived as a valuable resource to optimize patient care by providing patients with indepth education as it relates to their prescribed medications and disease states. These identified benefits of MTM clinic lead to frequent patient referrals specifically for aid with medication adherence and disease state management.

\footnotetext{
Mansi SHAH. PharmD, BCACP. Clinical

Pharmacist/Assistant Professor, Department of Pharmacy Practice, University of Illinois, Chicago IL (United States). mshah37@uic.edu

Anna MARKEL VAYSMAN. PharmD, BCPS, AE-C Clinical Pharmacist/Assistant Professor, Department of Pharmacy Practice, University of Illinois, Chicago IL (United States).

Lori WILKEN. PharmD, BCACP, AE-C, TT-S. Clinical Pharmacist/Assistant Professor. Department of Pharmacy Practice, University of Illinois, Chicago IL (United States).
}

Keywords: Medication Therapy Management; Professional Practice; Academic Medical Centers; Personal Satisfaction; Attitude of Health Personnel; Pharmacists; United States

\section{CONSULTA DE GESTION DE LA FARMACOTERAPIA: PERCEPCIÓN DE LOS PROFESIONALES DE LA SALUD EN UN CENTRO MÉDICO UNIVERSITARIO}

\section{RESUMEN}

Objetivo: Determinar la percepción general y la utilización de los servicios de una consulta de gestión de la farmacoterapia (MTM) por profesionales de la salud de una centro médico universitario grande y urbano.

Métodos: Este fue una encuesta transversal y anónima enviada a 195 profesionales de la salud, incluyendo médicos enfermeras y farmacéuticos del Centro de Salud Ambulatorio de la Universidad de Illinois, para determinar su percepción y utilización de la consulta de MTM. El cuestionario consistía en 12 preguntas y fue aplicado a través de una aplicación online segura.

Resultados: Sesenta y dos (32\%) profesionales de la salud completaron la encuesta. El 82\% estaban familiarizados con la consulta de MTM y el 63\% habían remitido pacientes a esta consulta. La adherencia a la medicación y la gestión de la enfermedad fueron los dos motivos más frecuentes de remisión. La falta de conocimiento sobre el procedimiento adecuado de remisión fue la razón más predominante para no remitir pacientes a la consulta de MTM. De los profesionales que conocían los servicios de MTM, el 44\% evaluó la atención como 'excelente', el 44\% como 'buena', el 5\% como regular' y el 0\% como 'pobre'. Las fortalezas de la consulta de MTM incluyeron la educación intensa de los pacientes, el seguimiento intensivo, y la reconciliación de la medicación detallada proporcionada por los farmacéuticos clínicos. De entre los que estaban familiarizados con la consulta de MTM, las recomendaciones incluyeron: aumentar los esfuerzos de marketing para incrementar el conocimiento de la consulta de MTM, crear acuerdos colaborativos de práctica entre farmacéuticos del MTM y médicos, y asegurar que las notas clínicas fuesen más breves. Conclusión: En una institución académica grande y urbana, la consulta de MTM se percibió como un recurso valioso para optimizar la atención a pacientes proporcionado educación profunda asociada a medicamentos prescritos y enfermedades. Estos beneficios identificados de la 
consulta de MTM produjeron frecuentes remisiones de pacientes, específicamente para ayuda con su adherencia a la medicación y gestión de la enfermedad.

Palabras clave: Gestión de la Farmacoterapia; Práctica Profesional; Centros Médicos Académicos; Satisfacción Personal; Actitud del Personal de Salud; Farmacéuticos; Estados Unidos

\section{INTRODUCTION}

Increased collaboration amongst healthcare providers has shown to favorably impact patient outcomes. ${ }^{1-3}$ The role of pharmacists has evolved from traditional dispensing to providing comprehensive medication therapy management in collaboration with other healthcare providers. According to the 2009 National Pharmacist Workforce Survey, pharmacists across the country are spending less time performing distributive functions and more time providing direct patient care and education. ${ }^{4}$ The Medicare Prescription Drug Improvement and Modernization Act (MMA) of 2003 required that Medicare Part D insurers provide medication therapy management (MTM) services to selected beneficiaries, in order to optimize therapeutic outcomes by improving medication use and reducing adverse drug events. In 2010, Centers for Medicare and Medicaid Services (CMS) revised the requirements for MTM and as a result all Part D sponsors are required to provide MTM services to their beneficiaries by a pharmacist or other qualified healthcare provider. ${ }^{5,6}$ CMS evaluates Part D MTM programs annually, and as MTM evolves and the role of pharmacists providing patient care becomes more defined, it is essential that pharmacists build close collaborative relationships with other healthcare providers to enhance patient outcomes. Studies have shown that collaboration between physicians and pharmacists can improve patient safety, reduce health care costs, and improve the quality of care provided. ${ }^{7,8}$

Information on the value of a hospital based MTM clinic as perceived by healthcare physicians is limited. However, in the community setting, Mcgrath and colleagues evaluated physician perceptions of a community pharmacist run MTM clinic and found a lack of physician understanding on the role of MTM services along with a concern about the clinical expertise of a community pharmacist. $^{9}$ Alkahateeb and colleagues found that physicians attitudes toward a community pharmacist run clinic were not that favorable in respect to making independent decisions about drug therapy or providing education for specific disease states. ${ }^{10} \mathrm{~A}$ qualitative study was conducted at the Fairview Health Services, in which six primary care physicians that worked closely with MTM pharmacists were interviewed. The study found that the providers valued MTM pharmacists and found them to be an integral part of the team secondary to their expertise in medications. ${ }^{11}$ Current literature, has not yet evaluated the perception of healthcare providers through a quantitative survey on the role of MTM in a hospital based setting.

The University of Illinois Hospital and Health Sciences System (UI Health), is a large, urban academic institution. The MTM clinic at UI Health, has been established for over 10 years. The mission of the MTM clinic is to assist patients taking multiple long-term medications with medication adherence and disease state management, ultimately leading to improvement in healthcare outcomes and prevention of drug related problems. The MTM clinic is a referral based, pharmacist run clinic which currently provides MTM services to approximately 150 active patients, with new patients being enrolled in the clinic on an ongoing basis. There are currently three pharmacists solely dedicated to the MTM clinic along with four additional pharmacists that divide their time between MTM clinic and other clinics. Furthermore, there is one full time pharmacy technician, one student extern, and several PharmD students that assist with MTM clinic ancillary activities. Additionally, PGY1 and PGY2 residents and PharmD candidates rotate through the clinic.

Approximately 1800 prescriptions are filled per month by patients in the MTM clinic, with each patient averaging about 15 medications. ${ }^{12}$ The clinical services have evolved into a comprehensive program providing five distinct service areas: access, adherence, coordination of care, medication therapy review, and education. During the initial visit, patient information is collected through an indepth patient interview, focusing on medication reconciliation, and addressing any immediate drugrelated problems. Routine visits are scheduled monthly or more frequently based on individual patient needs, to further evaluate drug therapy, adverse effects, and adherence. When necessary, pharmacists contact physicians, nurses, social workers, and other healthcare providers to offer recommendations and implement changes to enhance patient care since a collaborative practice agreement is currently not in place. A collaborative practice agreement is an agreement between the pharmacist and authorized healthcare provider that allows pharmacists to modify, prescribe, or discontinue a medication regimen. All visits are documented in the electronic medical record through a formal SOAP note. Currently the MTM clinic is not being reimbursed for the services provided, however research is being conducted to evaluate avenues in billing. The clinic is a subset of an outpatient pharmacy, enabling patients to have their medications filled at the pharmacy. This model of MTM clinic integrates collaboration between various healthcare providers to optimize patient care. Despite the longevity of the service, there has not been a formal assessment of how it is perceived by other healthcare providers at UI Health. Gaining insight into physician attitudes toward pharmacist provision of MTM is important to advance clinical practice.

The primary objective was to evaluate the overall perception of various healthcare professionals in regards to the service provided by the MTM 
pharmacists. Secondary outcomes included assessing methods to improve MTM services and to understand the perceived role of the MTM clinic by other healthcare professionals in a university medical care setting.

\section{METHODS}

This was a cross-sectional, prospective, anonymous survey sent to 195 healthcare professionals including physicians, nurses, and pharmacists at the UI Health outpatient care center. Subjects were recruited using clinic rosters which included the contact information for each of the providers at the clinics located in the outpatient care center. Healthcare professionals, limited to physicians, pharmacists, and nurses between the ages of 18 and 85 employed in the outpatient care center at UI Health were included in the study. Any healthcare provider that has ever worked at the MTM clinic was excluded from the study. This study took place between January and February of 2012 over a six week course.

The survey included twelve questions which took approximately five minutes to complete. The survey instrument was not validated, however questions were created after reviewing current literature on the appropriate design of a validated survey. ${ }^{13,14}$ The survey instrument included questions addressing information about the type of provider, their specialty, knowledge, understanding, and utility of the MTM clinic, and their perception of the strengths and weakness of the MTM clinic. Nine questions were multiple choice and three questions were open ended, fill in the blank questions. Subjects were not allowed to skip any of the twelve questions. All questions were mutually exclusive and open ended questions were grouped together based on similar themes. Survey data was administered and managed using Research Electronic Data Capture (REDCap). After the initial survey was sent out, two follow up reminders were sent two weeks apart. The study was approved by the UI Health Institutional Review Board. Statistical analysis was conducted by the UI Health Center for Clinical and Translational Science (CCTS) using descriptive analysis such as frequencies and medians. Fischer's exact test was used to evaluate statistical significance. All analyses were performed in SPSS. Two sided p-values $<0.05$ were considered statistically significant.

\section{RESULTS}

Of the 195 surveys that were sent, 62 healthcare professionals (32\%) completed the survey. None of the surveys were non-deliverable. All surveys were completed in full, thereby enabling researchers to use all responses in statistical analysis. Of the 62 completed surveys, the majority were physicians $(66 \%)$, followed by nurses $(19 \%)$ and pharmacists $(15 \%)$. At the time of the survey, the healthcare professionals worked in the internal medicine (44\%), cardiology (20\%), or pulmonary (11\%) clinics (Table 1). From the sample group, $82 \%$ were familiar with the MTM clinic, and $63 \%$ of them had

\begin{tabular}{|r|c|}
\hline \multicolumn{2}{|c|}{ Table 1. Demographics of respondents } \\
\hline Profession & Percent \% $(\mathrm{n}=62)$ \\
\hline & \\
Physician & 66 \\
Pharmacist & 19 \\
Nurse & 15 \\
\hline Clinic Employment & \\
Internal Medicine & 44 \\
Pulmonary & 11 \\
Cardiology & 10 \\
Antithrombosis & 10 \\
Other & 25 \\
\hline
\end{tabular}

previously referred patients to the clinic. Fifty-three percent $(53 \%)$ of providers have referred between 1-5 patients and $28 \%$ have referred $>10$ patients.

Medication adherence and disease state management was the most common reason for referral, according to $97 \%$ of respondents $(p=0.006)$. There was no statistical difference between professions or clinics with regard to the familiarity of the MTM clinic $(p=0.22 \& p=0.62)$. Additionally, there was no statistical significance in rate of referral $(p=0.40 \& p=0.76)$ amongst the responders or various clinics. Lack of knowledge on the appropriate referral procedure was the main reason for not referring patients to the MTM clinic. According to healthcare professionals the primary role of the MTM clinic was to aid with adherence and disease state management (92\%; $p=0.02)$ versus dispense medications $(4 \%)$ and place medications in pillboxes for patients $(4 \%)$ (Table 2). There was no statistical difference in response between the various types of providers.

Of the providers that were aware of MTM services, $44 \%$ rated care provided by MTM pharmacists as 'excellent', $44 \%$ as 'good', 5\% as 'fair', and 0\% stated 'poor'. Approximately 39\% of healthcare professionals admitted to reading the MTM pharmacist clinical notes, $46 \%$ stated that they 'sometimes' read the notes, and 15\% reported that they 'do not read the notes'. There was no statistical difference in response rate between the various types of providers. A subset analysis of the providers that referred patients to MTM clinic was completed. Of these providers, $44 \%$ rated care given by MTM pharmacists as 'excellent', $30 \%$ as 'good', and $8 \%$ as "fair." Approximately $44 \%$ of these providers stated they read the MTM clinical notes, 29\% stated they 'sometimes' read MTM notes, and $9 \%$ stated they 'do not read the notes'.

\begin{tabular}{|c|c|}
\hline Table 2. Results $(\mathrm{n}=62)$ & \\
\hline Question & Percent \% \\
\hline What is the Primary Role of MTM clinic? & \\
\hline Dispense Medications & 5 \\
\hline Place medications in pillboxes & 3 \\
\hline $\begin{array}{r}\text { Aid with adherence and disease state } \\
\text { management }\end{array}$ & 92 \\
\hline Number of Patients Referred to MTM clinic & \\
\hline $1-5$ & 53 \\
\hline $6-10$ & 19 \\
\hline$>10$ & 28 \\
\hline $\begin{array}{l}\text { How would you rate the care your patients } \\
\text { receive from MTM clinic }\end{array}$ & \\
\hline Poor & 0 \\
\hline Fair & 12 \\
\hline Good & 44 \\
\hline Excellent & 44 \\
\hline
\end{tabular}


Strengths of the MTM clinic identified by healthcare providers included in-depth education and counseling to patients about their medications, close follow-up, effective communication with providers, and detailed medication reconciliation provided by MTM clinical pharmacists. Recommendations to improve the clinic included; heighten marketing to raise awareness of the MTM clinic, create collaborative practice agreements for more effective and efficient patient care, and ensure that notes in the electronic medical record are concise.

\section{DISCUSSION}

This study demonstrates the positive relationship between healthcare providers and MTM clinic pharmacists in a large, urban academic institution. Contrary to the findings of both McGrath $^{8}$ and Alkhateeb $^{9}$, this survey results validate that the majority of healthcare providers view MTM clinic pharmacists as valuable patient care providers, beyond the traditional role of medication dispensing. The findings support the emerging role of pharmacists in direct patient care by improving adherence and disease state management. Providers at UI Health viewed the MTM clinic as a means of providing patients with more in depth education, improving medication adherence and disease state management, and completing detailed medication reconciliation which is of great value in their practice.

The survey also identified, that despite the longevity of the UI Health MTM clinic program, many providers are still unaware of the programs existence. This demonstrates the need for increased marketing, and provider detailing regarding the MTM services. Furthermore, creating a standardized referral process may make it more convenient for providers to send their patients to the MTM clinic. After this study, UI Health is working on developing an electronic referral form for all clinics and has created brochures to place in physician offices to increase awareness of the program. This may increase the number of referrals for MTM clinic and simplify the process.

Lastly, many nurses felt there should be increased collaboration between physicians and pharmacists to eliminate themselves as the mediator. Multiple physicians supported the need for more defined collaborative agreements between physicians and pharmacists, stating that this can positively impact their work flow due to fewer interruptions for simple tasks such as medication refills and routine laboratory evaluations. Based on these recommendations, the UI Health MTM clinic pharmacists in conjunction with the physicians are currently working on developing collaborative protocols for hypertension, diabetes, and refills for commonly prescribed medications. Furthermore, healthcare providers suggested the documentation in the electronic medical record be simplified so that notes are shorter and easier to read since many providers are not reading MTM clinic notes. As a result, many times recommendations that are made by an MTM clinic pharmacist within the notes are not implemented by providers. If the pharmacist obtained approval to change medications by other physicians and updated the medications regimen in the MTM notes, many times they are not caught by providers that do not read the MTM clinic notes. Currently, the MTM clinic pharmacists are reevaluating the note template and consulting other MTM clinics to evaluate methods in shortening the MTM notes.

This study was conducted in a single academic institution, where clinical pharmacy services are readily available and well established in a majority of the outpatient clinics and inpatient services. Therefore, many healthcare providers are familiar with the evolving role of pharmacists and are more accepting towards recommendations and collaboration. Although the results can't be generalized to all practice settings, it can be deduced that in a similar institution the results would be reproducible. Another limitation includes the low response rate and lack of incentive for providers to complete the survey. The response rate amongst pharmacists (63\%), was greater than nurses $(50 \%)$ and physicians (49\%). Nonresponse bias threatens the validity of the research. However, the response rate was greater than the average for electronic surveys. ${ }^{15}$ Finally, the survey questions were not validated due to time constraints and lack of resources; however, multiple references were utilized to design a validated questionnaire.

\section{CONCLUSIONS}

Physicians, nurses, and pharmacists alike signify that MTM clinic is a valuable resource to optimize patient care mainly utilized to improve medication adherence, and to provide more in-depth education. Further improvements can be made by increasing provider awareness of the MTM clinic through marketing efforts, as well as creating a more collaborative practice with physicians for additional autonomy in titrating medications and ordering clinically relevant laboratory values. The clinic plays a vital role in a large, urban, academic institution by optimizing patient medication adherence, and contributing to disease state management. From this study it can be concluded, that a similar pharmacist-run clinic would be of great value at other institutions as well and perceived as a great asset and value within the practice.

\section{CONFLICT OF INTEREST}

No potential conflicts of interest or financial disclosures relevant to this article were reported by any of the authors.

1. Carter BL, Clarke W, Ardery G, Weber CA, James PA, Vander Weg M, Chrischilles EA, Vaughn T, Egan BM; Collaboration Among Pharmacists Physicians To Improve Outcomes Now (CAPTION) Trial Investigators. A cluster- 
randomized effectiveness trial of a physician-pharmacist collaborative model to improve blood pressure control. Circ Cardiovasc Qual Outcomes. 2010;3(4):418-423. doi: 10.1161/CIRCOUTCOMES.109.908038

2. Grumbach K, Bodenheimer T. Can health care teams improve primary care practice? JAMA. 2004;291(10):1246-1251.

3. Chisholm-Burns MA, Kim Lee J, Spivey CA, Slack M, Herrier RN, Hall-Lipsy E, Graff Zivin J, Abraham I, Palmer J, Martin JR, Kramer SS, Wunz T. US pharmacists' effect as team members on patient care: systematic review and metaanalyses. Med Care. 2010;48(10):923-933. doi: 10.1097/MLR.0b013e3181e57962

4. Pharmacy Manpower Project Inc. Final Report of the National Pharmacist Workforce Study 2009. http://www.aacp.org/resources/research/pharmacymanpower/Documents/2009\%20National\%20Pharmacist\%20Workfor ce\%20Survey\%20-\%20FINAL\%20REPORT.pdf (Accessed August 7, 2012).

5. Government Printing Office. Medicare Prescription Drug, Improvement, and Modernization Act of 2003. http://frwebgate.access.gpo.gov/cgi-bin/getdoc.cgi?dbname=108_cong_public_laws\&docid=f:publ173.108 (Accessed August 30, 2012).

6. Centers for Medicare \& Medicaid Services. Fact Sheet: 2011 Medicare Part D Medication Therapy Management (MTM) Programs. http://www.cms.gov/PrescriptionDrugCovContra/downloads/MTMFact-Sheet2011063011Final.pdf (Accessed November 1, 2012).

7. Webb EC. Prescribing medications: changing the paradigm for a changing health care system. Am $\mathrm{J}$ Health Syst Pharm. 1995;52(15):1693-1695.

8. Thompson CA. Physician leaders hear details on pharmacist collaborative drug therapy management. Am $\mathrm{J}$ Health Syst Pharm. 2001;58(10):843-846.

9. McGrath SH, Snyder ME, Dueñas GG, Pringle JL, Smith RB, McGivney MS. Physician perceptions of pharmacistprovided medication therapy management: qualitative analysis. J Am Pharm Assoc (2003). 2010;50(1):67-71. doi: 10.1331/JAPhA.2010.08186

10. Alkhateeb FM, Unni E, Latif D, Shawaqfeh MS, Al-Rousan RM. Physician attitudes toward collaborative agreements with pharmacists and their expectations of community pharmacists' responsibilities in West Virginia. J Am Pharm Assoc (2003). 2009;49(6):797-800. doi: 10.1331/JAPhA.2009.08111

11. Maracle H, Ramalho de Oliveira D, Brummel A. Primary Care Providers' experiences with Pharmaceutical Care-based Medication Therapy Management Services. Innovations in pharmacy. 2012;3(1):72.

12. Kliethermes MA, Schullo-Feulner AM, Tilton J, Kim S, Pellegrino AN. Model for medication therapy management in a university clinic. Am J Health Syst Pharm. 2008;65(9):844-856. doi: 10.2146/ajhp070338

13. Questionnaire Design. http://biostat.mc.vanderbilt.edu. (Accessed August 30, 2012).

14. McColl E, Jacoby A, Thomas L, Soutter J, Bamford C, Steen N, Thomas R, Harvey E, Garratt A, Bond J. Design and use of questionnaires: a review of best practice applicable to surveys of health service staff and patients. Health Technol Assess. 2001;5(31):1-256.

15. Fincham JE. Response rates and responsiveness for surveys, standards, and the Journal. Am J Pharm Educ. 2008;72(2):43. 